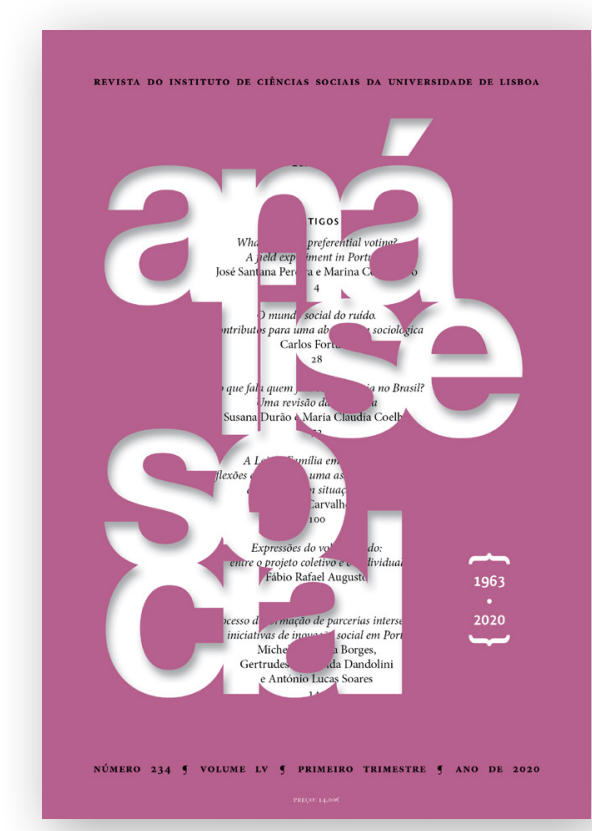

FÁBIO RAFAEL AUGUSTO

\title{
Expressões do voluntariado: entre o projeto coletivo e o individual
}

\author{
Análise Social, LV (1. $\left.{ }^{\circ}\right), 2020$ (n. $\left.{ }^{\circ} 234\right)$, pp. 144-167 \\ https://doi.org/10.31447/Asooo32573.2020234.06 \\ ISSN ONLINE 2182-2999
}


Análise Social, 234, LV (1. $), 2020,144-167$

Expressões do voluntariado: entre o projeto coletivo e o individual. O voluntariado insere-se no âmbito de um conjunto de transformações sociais que marcaram a "entrada" numa nova fase da modernidade. Nesta transição, tanto a prática como as organizações que a acolhem passaram a enfrentar novos desafios associados, sobretudo, à emergência dos processos de individualização e reflexividade. A Re-food representa uma iniciativa de apoio alimentar, relativamente recente, que tem tido a capacidade para se adaptar a uma realidade (a nacional) que se caracteriza por uma certa "apatia participativa", como também, a diferentes perfis de voluntários e, portanto, a diferentes expectativas e interesses associados à prática. Com base numa pesquisa etnográfica, procurar-se-á perceber o que poderá ter suscitado o crescimento da iniciativa e de que forma os seus voluntários manifestam "sintomas" da referida transição.

PALAVRAS-CHAVE: voluntariado; individualização; reflexividade; Re-food.

Expressions of volunteering: between the collective and individual project. Volunteering is part of a series of social transformations that marked the "entry" into a new phase of modernity. In this transition both the practice and the organizations that promote it have come to face new challenges associated with above all, the emergence of processes of individualization and reflexivity. Re-food is a relatively recent food aid initiative that has had the capacity to adapt, not only, to a (national) reality characterized by a certain "participatory apathy", but also to different profiles of volunteers and thus to different expectations and interests. Based on ethnographic research, this article seeks to explain the growth of the initiative and how its volunteers manifest "symptoms" of the aforementioned transition.

KEYWORDS: volunteering; individualization; reflexivity; Re-food.

https://doi.org/10.31447/ASO0032573.2020234.06 


\section{Expressões do voluntariado: entre o projeto coletivo e o individual}

\section{INTRODUÇÃO}

Ainda que a palavra "voluntariado" possa remeter para uma dada realidade relacionada com uma vontade de ajudar o outro, que se traduz em ações concretas assentes no princípio da solidariedade, trata-se de um fenómeno complexo e multifacetado. Como tal, esta prática que remonta à Idade Média (Wilson e Pimm, 1996) e adquire particular relevância nas sociedades modernas, tem sido alvo de múltiplas conceptualizações.

Face à multiplicidade de abordagens e de forma a enquadrar os debates que serão apresentados nas próximas secções, interessa mobilizar o conceito de voluntariado formal. Nesta vertente, a prática do voluntariado encontra-se relacionada com o trabalho desenvolvido por organizações que prestam, entre outros, serviços sociais (Hardlll e Baines, 2011). No presente artigo, interessa, justamente, analisar o voluntariado que se insere no âmbito de uma iniciativa de apoio alimentar (Re-food) e, particularmente, o voluntariado daqueles que atuam no terreno e em contacto, mais ou menos direto, com os beneficiários da organização em causa.

A escolha da Re-food relaciona-se com o seu rápido crescimento e com os fatores que conduziram ao mesmo, em que a preocupação em responder a diferentes necessidades que emergem de um universo heterogéneo de voluntários ganha particular destaque. Assim, a Re-food é analisada enquanto uma organização que surge num contexto onde "novas" e "velhas" exigências relacionadas com a prática do voluntariado coexistem.

Posto isto, este artigo propõe-se debater o voluntariado à luz de alguns dos pressupostos lançados por teóricos de referência como Ulrich Beck, Anthony Giddens, Zygmunt Bauman e Scott Lash, que abordaram temas como a sociedade de risco, a individualização, a reflexividade e a destradicionalização nas sociedades contemporâneas. Numa primeira fase, o artigo procura lançar algumas linhas orientadoras de resposta a questões de fundo como: que mudanças 
tem vindo a enfrentar o voluntariado? Como é que esta prática se manifesta e materializa nas sociedades contemporâneas? Quais os desafios que as organizações que promovem o voluntariado enfrentam nos dias de hoje? Numa segunda fase, e tendo por base a análise realizada à Re-food, procurar-se-á lançar alguns indícios de resposta a questões que se relacionam: (i) com o possível enquadramento da Re-food no âmbito de um alargado leque de transformações sociais que tiveram um impacto profundo na forma como os sujeitos "olham" para o voluntariado e na forma como o experienciam; (ii) com o modo como a iniciativa se adaptou e foi capaz de mobilizar indivíduos pertencentes a um universo heterogéneo de voluntários (com diferentes expectativas e interesses). As linhas de resposta a estas questões, que serão expostas de seguida, contribuirão para a compreensão de uma prática que expressa o dinamismo da sociedade civil, na qual os conceitos de cidadania ativa e participada ganham ênfase.

Nos pontos que se seguem, parte-se da descrição da metodologia seguida para uma breve apresentação de alguns dados estatísticos relativos à prática do voluntariado no contexto nacional para que, num terceiro ponto, esta prática seja debatida segundo os pressupostos teóricos anteriormente referidos. Além disso, será fornecida uma ilustração empírica a partir do caso de uma organização de combate à pobreza e ao desperdício alimentar (Re-food), que constitui um exemplo de uma iniciativa que cresceu e se expandiu num contexto caracterizado por uma certa "apatia participativa" e pela coexistência de diferentes perfis de voluntários. A análise desta organização assenta numa pesquisa etnográfica e, particularmente, na análise de discursos de voluntários em contexto de observação participante.

\section{METODOLOGIA}

Do ponto de vista metodológico, parte-se da análise de dados primários recolhidos através de observação participante num núcleo da Re-food, localizado no distrito de Lisboa. ${ }^{1}$ De forma a garantir a entrada e imersão no terreno de pesquisa o investigador adotou também o papel de voluntário. $\mathrm{O}$ trabalho de campo desenvolveu-se de forma intensiva durante três meses (de fevereiro a abril de 2018$)^{2}$, tendo o voluntariado ocorrido duas vezes por semana durante quatro horas (total semanal). Durante este período, o voluntário

1 De forma a salvaguardar os participantes envolvidos no estudo, considerou-se pertinente não especificar o núcleo da Re-food onde a investigação ocorreu.

2 O período oficial de recolha de dados foi antecedido por um período exploratório (entre outubro de 2016 e maio de 2017) que possibilitou ao investigador conhecer o terreno de pesquisa e adaptar os instrumentos de recolha de dados à realidade encontrada. 
etnógrafo ${ }^{3}$ levou a cabo atividades relacionadas com a distribuição de bens alimentares a beneficiários da iniciativa.

Além do estabelecimento de um protocolo de cooperação com a Re-food, todos os documentos utilizados no âmbito do estudo - consentimento informado, guiões de entrevista, acordo de cooperação e folheto informativo do projeto - foram aprovados pela Comissão de Ética da instituição de acolhimento.

Os dados que irão ser apresentados decorrem, portanto, da observação realizada e da materialização da mesma, numa primeira fase, em ficheiros de áudio (com recurso a gravador) e, numa segunda, em documentos de texto com base nas gravações realizadas. Tais apontamentos incluem, não só, as descrições das situações vivenciadas, como também tentativas de reprodução dos discursos que cativaram a atenção do voluntário etnógrafo.

$\mathrm{O}$ recurso ao método de observação participante permitiu explorar, por um lado, as dinâmicas relacionais estabelecidas entre voluntários e beneficiários e, por outro, o modus operandi da iniciativa Re-food. Assim, a observação ocorreu a dois níveis: (i) relacional; e (ii) organizacional. Estes níveis de análise permitiram partir para a compreensão da prática do voluntariado num contexto marcado por processos que conduzem os indivíduos a pensar-se a si próprios e aos seus percursos de vida, enquanto fruto de uma responsabilização "imposta" pela emergência daquilo que Beck (2002) designa por categorias zombie. Permitiram também perceber a forma como a iniciativa funciona e, portanto, aquilo que a define e que poderá estar por detrás do seu rápido crescimento e da sua capacidade para mobilizar um "corpo" heterogéneo de voluntários.

\section{VOLUNTARIADO EM PORTUGAL:}

OS NÚMEROS QUE ESPELHAM UMA CERTA “APATIA PARTICIPATIVA”

A investigação desenvolvida em Portugal na área do voluntariado enquanto principal objeto de estudo e de reflexão teórico-conceptual ainda se encontra num estado algo incipiente, apesar da existência de alguns trabalhos importantes nesta área (Delicado, Almeida e Ferrão, 2002; Amaro et al., 2012; Ferreira, Serapioni e Maneca, 2013).

Além disso, diferentes estudos recorrem a abordagens, definições e metodologias específicas e particulares para analisar a prática do voluntariado, o que pode contribuir para causar alguma indefinição em torno do fenómeno

3 Garthwaite (2016) usou o termo "voluntário etnógrafo" para se referir ao duplo papel (enquanto investigador e enquanto voluntário) que assumiu numa iniciativa de apoio alimentar. 
e para complexificar a prossecução de estudos futuros. Denota-se, assim, a necessidade de adotar ferramentas conceptuais e metodológicas que permitam comparar os dados recolhidos tanto a nível nacional como internacional.

Fruto dos desafios identificados, interessa referir que os dados apresentados nesta secção foram recolhidos por autores e organizações que seguem metodologias distintas, pelo que a leitura dos números aqui "lançados" não deve descurar o contexto de pesquisa em que os mesmos se inserem.

De acordo com os dados recolhidos por Ferreira, Serapioni e Maneca (2013), através de fontes como Vala e Villaverde Cabral (1999); Delicado (2002) e Eurobarómetro $(2007,2011)$ denota-se uma tendência de redução da percentagem de pessoas que realizam voluntariado no contexto português, desde 1990, tendo esta redução estabilizado no período de 2007 até 2011, como se pode verificar.

\section{FIGURA 1}

Participação da sociedade portuguesa no voluntariado

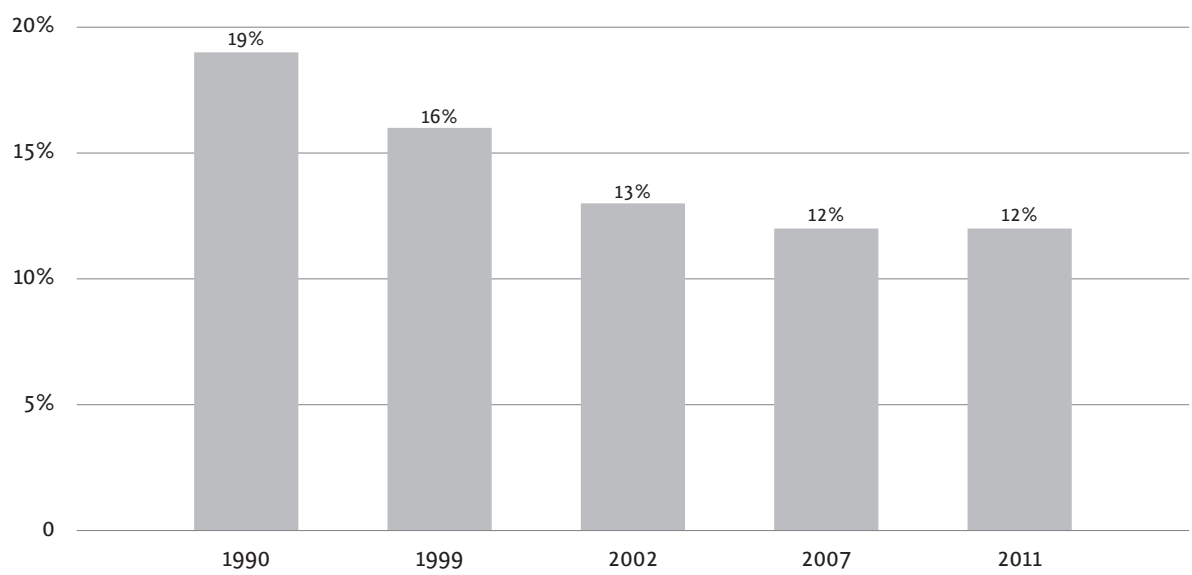

Fonte: Elaboração própria com base nos dados disponibilizados por Ferreira, Serapioni e Maneca (2013).

Estes dados mostram a existência de baixas taxas de voluntariado em Portugal nas suas diversas tipologias (formal, informal e de proximidade ${ }^{4}$ ), principalmente, quando comparado com outros países da Europa Continental e do Norte.

4 O voluntariado formal diz respeito à "participação no trabalho de organizações de voluntariado ou de beneficência"; o informal prende-se com "o nível de ajuda a outros (excluindo familiares, trabalho em organizações de voluntariado); e o de proximidade implica "ajudar ou participar em atividades organizadas a nível local” (Ferreira, Serapioni e Maneca, 2013, p. 64). 
As justificações que têm vindo a ser apontadas para uma certa "apatia participativa" no contexto português são de ordem económica, social e política, tais como: (i) um país caracterizado por um longo período ditatorial, onde a prática associativa não era incentivada; (ii) uma sociedade marcada por uma cultura cívica muito incipiente, verificável, por exemplo, nas baixas taxas de participação associativa e eleitoral; (iii) a pouca expressão de classes média-alta e alta, onde, segundo estudos internacionais, a prática de voluntariado teria maior expressão; e (iv) um mercado de trabalho precário que não permite compatibilização com o voluntariado (Delicado, Almeida e Ferrão, 2002). Além disso, são também apontadas justificações que se prendem com a ausência de esforços por parte das entidades públicas e das políticas no sentido de promover o voluntariado, com a pouca visibilidade do mesmo e com a ausência de formação na escola e universidades (Ferreira, Serapioni e Maneca, 2013).

Também a informalidade das relações sociais que caracteriza a sociedade- providência ${ }^{5}$ descrita por Boaventura de Sousa Santos (1995) poderá ajudar a perceber a reticência, por parte dos portugueses, em participarem por intermédio da prática do voluntariado, essencialmente, na tipologia formal. Ainda que se verifiquem baixos níveis de participação em organizações formais, a sociedade portuguesa valoriza e promove a solidariedade através da prestação de cuidados informais, por exemplo, a vizinhos e familiares. Denota-se, portanto, que a não inclusão de determinadas práticas solidárias caracterizadas por um maior nível de informalidade nos indicadores que servem as estatísticas em torno do voluntariado acaba por condicionar a leitura que é feita das mesmas.

Tal como é apontado por Monteiro (2008), o voluntariado, em Portugal, esteve numa fase inicial muito ligado à igreja, nomeadamente através de atividades de caridade social, e mais tarde o trabalho voluntário passa a ligar-se também a valores de defesa dos direitos humanos, de solidariedade, e relacionados com questões ambientais. Denota-se também que o voluntariado possui uma maior expressão no setor dos serviços, sendo que a participação nas áreas culturais é relativamente reduzida, tal como ocorre noutros países do Sul da Europa (Ferreira, Serapioni e Maneca, 2013).

Dados mais recentes do The World Giving Index, disponibilizados pela Charities Aid Foundatin $(2011,2012,2013,2014,2015,2016)^{6}$ mostram que a partir de 2012 houve um aumento expressivo da percentagem de portugueses

5 Entendida como um conjunto de "redes de relações de interconhecimento, de reconhecimento mútuo e de entreajuda baseadas em laços de parentesco e de vizinhança, através das quais pequenos grupos sociais trocam bens e serviços numa base não mercantil e com uma lógica de reciprocidade semelhante à da relação de dom estudada por Marcel Mauss" (Santos, 1993, p. 46). 6 Para mais informações: https://www.cafonline.org/. 
que doam o seu tempo sob a forma de voluntariado, verificando-se uma redução ligeira em 2014 e um novo aumento, também pouco expressivo em 2016, tal como se pode ver.

\section{FIGURA 2}

Participação da sociedade portuguesa no voluntariado.

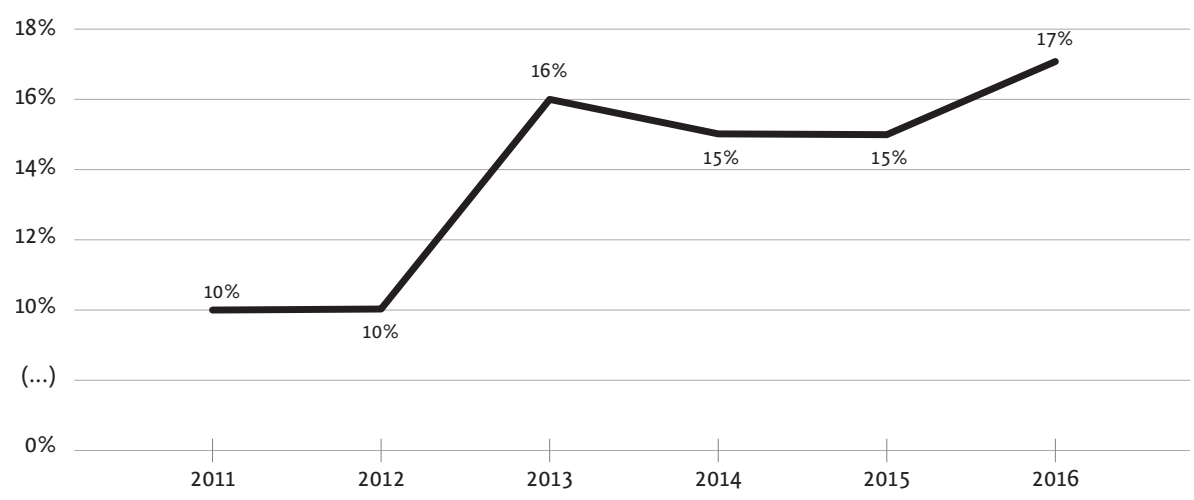

Fonte: Elaboração própria com base nos dados disponibilizados por Charities Aid Foundatin (2011-2016).

Este aumento, a par do que havia sido referido no estudo coordenado por Rogério Roque Amaro (2012), pode estar relacionado, entre outros fatores, com uma maior visibilidade da prática de voluntariado a vários níveis (social, científica e política), onde eventos como o Ano Internacional do Voluntariado em 2001 e o Ano Europeu em 2011 podem ter sido cruciais. Além disso, a crise económica e financeira que se fez sentir a partir de 2008 e o consequente agravamento das situações de pobreza e exclusão social, poderá ter sensibilizado a população portuguesa a contribuir através do voluntariado.

Ainda que a participação da sociedade portuguesa possua, atualmente, números mais elevados quando comparados com o período de dez anos que vai desde 2002 até 2012, o país continua a caracterizar-se por baixos níveis de voluntariado. No âmbito do estudo levado a cabo pela Charities Aid Foundation e com base nos dados recolhidos em 2016, Portugal encontrava-se na posição 90 (situando-se entre o Iraque - 89 - e o Equador - 91 -) numa lista de 140 países. Este estudo baseia-se na análise das respostas às seguintes perguntas: "realizou alguma das seguintes ações no último mês: (i) ajudou algum estranho ou alguém que não conhecia e precisava de ajuda? (ii) doou dinheiro para uma instituição de caridade? e (iii) realizou voluntariado para uma organização?”.

No que diz respeito às organizações que promovem a prática do voluntariado, dados relativos a 2014 apontavam para um universo de 17012 
Organizações Não Governamentais (ONG) a atuar no contexto nacional. Destas, $37,5 \%$ tinham como principal grupo de atividade o dos serviços sociais (Franco, 2015), onde se inserem as Instituições Particulares de Solidariedade Social (IPSS), sendo nesta realidade que é possível enquadrar a Re-food que, em 2013, adquiriu este estatuto. Neste âmbito, interessa também destacar que $64 \%$ do total das IPss que atuam em Portugal acolhem voluntários na tipologia de voluntariado formal (Franco, 2015).

Os dados apresentados nesta secção dão a conhecer, ainda que de uma forma pouco aprofundada, um retrato, assente em números, da prática do voluntariado no contexto nacional. Verificando-se que, ao longo dos vários anos enunciados, tem sido uma prática com pouca expressão, particularmente quando se compara com o contexto internacional. Desta forma, parece fazer sentido a afirmação de que os números provenientes de diversas fontes e assentes em metodologias distintas espelham uma certa "apatia participativa". É neste contexto, e perante um conjunto de transformações sociais a explorar na secção seguinte, que se insere a iniciativa de apoio alimentar (Re-food) que será fruto de análise.

\section{RUMO AO PROJETO DO “EU”}

Traçado o cenário da realidade portuguesa, interessa neste ponto trazer para o debate uma questão que remete para as modalidades de envolvimento no trabalho voluntário, ou seja, para a forma como as pessoas se articulam em torno do voluntariado no contexto de processos de individualização e reflexividade que resultam da "chegada" a uma segunda fase da modernidade. No fundo, pretende-se responder à questão: como pensar em projetos coletivos numa altura em que o projeto do "eu" parece imperar?

Caracterizar a sociedade atual e as dinâmicas presentes na mesma tem conduzido a um debate aceso, particularmente nas ciências sociais. Para autores como Giddens, Beck e Lash, encontramo-nos numa segunda fase da modernidade. Para eles, a modernidade não se "esgotou" e o pós-modernismo não se cumpriu.

Enquanto Giddens (1997) aponta para uma modernidade tardia ou radicalizada, Beck (1992) refere a existência de uma segunda vaga da modernidade (sociedade do risco) e Bauman (2000) faz uso do termo modernidade líquida. Numa obra em conjunto, Beck, ,Giddens e Lash (200o) adotam o conceito de modernização reflexiva. Alguns dos elementos caracterizadores desta segunda fase da modernidade e que deixam na história a sociedade industrial dizem respeito aos processos de reflexividade e de individualização. 
No âmbito da sociedade de risco preconizada por $\operatorname{Beck}(1992,1999,2008)$, deu-se um conjunto de mudanças estruturais que conduziram ao fim da primeira vaga da modernização (industrialização). Na segunda fase, os indivíduos con(vivem) e racionalizam os riscos que advêm da primeira vaga, como por exemplo a poluição. As instituições, como a igreja e a família, que antes serviam de referências e nos ajudavam a organizar a vida perdem a sua centralidade e tornam-se categorias zombie. Cabe, assim, aos indivíduos tomar decisões sobre o seu destino, construindo de forma reflexiva as suas próprias biografias:

Thus structural change in the private sphere results in the individualization of social agents who then are forced to make decisions about whether and whom they shall marry, whether they shall have children, what sort of sexual preference they might have. Individuals must then, free of these structures, reflexively construct their own biographie [Beck, 1992, p. 3].

Estamos perante uma sociedade que lida com a incerteza face a riscos que ultrapassam o controlo dos seres humanos. Parece, de certa forma, fazer sentido afirmar que o indivíduo ganha autonomia na construção do seu percurso de vida, libertando-se das amarras de instituições que antes seriam decisivas nesse processo construtivo.

Deste modo, o sujeito encontra-se assim "liberto de laços comunais" e pode partir para a construção das "suas próprias narrativas biográficas". Sendo que a reflexividade, "essencialmente cognitiva", fornece as bases para a emergência do "eu". Por sua vez, o processo de individualização decorre de um processo de "descontextualização dos modos de vida característicos das sociedades industriais (classe, estrato, papel sexual, família)" e, posteriormente, de um processo de "recontextualização sobre bases que se oferecem ao indivíduo para construir, articular e pôr em cena uma trajetória pessoal" (Monteiro, 2004, p. 130).

Porém, e paradoxalmente, este processo de individualização não chegou por escolha dos indivíduos, mas impôs-se: "individualization is a social condition which is not arrived at by a free decision of individuals" (Beck e Beck-Gernsheim, 2002, p. 4).

Seguindo esta linha de pensamento, Bauman, ao caracterizar a nova fase da modernidade como líquida, e ao referir: "a situação presente emergiu do derretimento radical dos grilhões e das algemas que, certo ou errado, eram suspeitos de limitar a liberdade individual de escolher e agir" (Bauman, 2001, p. 11), vem também ele colocar um sujeito liberto, de certa forma, de estruturas do passado, no centro da equação. 
Na obra Modernização Reflexiva: Política, Tradição e Estética no Mundo Moderno", de 2000, que reúne contributos de Beck, Giddens e Lash, é possível verificar esta tendência de um certo empoderamento do sujeito: "quanto mais modernizadas são as sociedades, mais os agentes (sujeitos) adquirem a capacidade de refletir sobre as condições sociais da sua existência e de as mudar dessa maneira" (Beck, Giddens e Lash, 2000, p. 165).

À luz dos contributos expostos anteriormente denota-se a relevância do projeto do "eu". Neste sentido emerge uma questão: e o projeto do "nós"? E os laços sociais? Como explicar a prática de voluntariado num período marcado por escolhas individuais e assentes na reflexividade enquanto a capacidade de pensarmos sobre nós próprios e criarmos as nossas próprias biografias?

Face à caracterização realizada no ponto anterior, verifica-se que apesar da baixa participação dos portugueses através do voluntariado, o fenómeno possui alguma expressão, resta saber em que contornos, ou seja, como é que o voluntariado (co)existe num período marcado pelos fenómenos supramencionados? O voluntariado adquiriu, também ele, novos contornos e novos significados?

Face a questionamentos idênticos, Monteiro" (2004) afirma: "o projeto reflexivo que orienta o indivíduo na construção da sua identidade, em articulação dialógica com terceiros, vai conduzi-lo ao estabelecimento de um círculo de relações, que cada vez mais mantém ou modifica em função de interesses, identificações e necessidades, dir-se-ia mesmo um zapping identitário" (2004, p. 133).

Desta forma, a relação do sujeito com outros e o seu envolvimento em ações coletivas deixa de constituir um destino para passar a ser uma escolha livre e pensada em função dos processos de individualização e reflexividade, permitindo ao indivíduo emancipar-se. Perdem-se, assim, as comunidades no sentido mais tradicional para dar lugar a redes de indivíduos, onde a obrigação é substituída pela liberdade de escolha e o individualismo é articulado com "a necessária produção de laços sociais" (Monteiro, 2004, p. 133).

As novas formas de ação coletiva já não serão, desta forma, impostas aos indivíduos, partindo-se antes de negociações que articulem os seus interesses e permitam flexibilidade. Dando-se um "recuo do formalismo jurídico, rejeição dos quadros formais de organização [e] recusa de porta-vozes" (Monteiro, 2004, p. 134). Neste âmbito, Giddens (1990), que aponta para processos de

7 A inspiração para o debate que se apresenta nesta secção emerge, justamente, da obra "Associativismo e Novos Laços Sociais" de Alcides Monteiro (2004), e particularmente, da questão: “o que leva os indivíduos a unirem-se?", levantada pelo autor na página 118 da obra em causa. 
destradicionalização e para a perda da centralidade da família e da comunidade, refere a criação de laços de significado que assentam na capacitação dos próprios sujeitos.

No âmbito da transição para a segunda fase da modernidade, a prática do voluntariado e a forma como os indivíduos se envolvem com a mesma também adquire novos contornos. A este propósito, Monteiro (2008), assente nos contributos de Jean-Pierre Worms (2005) e Jacques Ion (1997), aponta para um novo perfil de voluntários que se diferencia de um perfil anterior. Enquanto no passado o envolvimento associativo valorizava moralmente os valores coletivos sobre os individuais, apresentando-se o voluntariado como um projeto "imposto" ao sujeito, valorizando-se a fidelidade e lealdade a uma associação que impunha regras (caracterizadas por uma certa inflexibilidade) ao indivíduo. Nos dias de hoje, o novo perfil caracteriza-se por atribuir centralidade ao projeto do "eu", onde mais do que pertencer a uma associação por longos períodos de tempo, aceitando as condições da mesma, o indivíduo move-se em torno de ações com que se identifique e que satisfaçam os seus objetivos.

Esta espécie de "zapping identitário" veio condicionar os dirigentes das associações que se veem perante uma nova forma de realizar voluntariado, onde "as noções de fidelidade e de lealdade permanecem importantes, mas encaradas de forma diferente: fidelidade a si próprio e aos seus objetivos" (Monteiro, 2008, p. 6). Uma metáfora interessante para caracterizar tal processo de transição pode ser descrita como a "passagem do selo ao post-it", sendo que "a filiação permanente ou a militância têm dado lugar a envolvimentos efémeros” (Monteiro, 2008, p. 6). Hustinx e Lammertyn (2003; 2004) recorrem a caracterizações como "collective and reflexive volunteering" para separar formas tradicionais de formas modernas de voluntariado.

Mais do que uma mudança quantitativa, o voluntariado enfrenta uma mudança qualitativa (transformações ao nível das motivações). Assim, denota-se a possibilidade de compatibilizar individualização e solidariedade com novas práticas de voluntariado (Hustinx e Lammertyn, 2004).

Porém, caracterizar a prática de voluntariado em torno destes dois tipos-ideais de voluntários (os do passado e os do presente) representa uma simplificação de uma realidade que pode ser bem mais complexa. Para Hustinx e Lammertyn (2004) é possível encontrar nas atuais práticas de voluntariado traços do passado e do presente sem que exista uma clara separação temporal da transição anteriormente descrita. A este respeito, Sanghera (2017) aponta para a existência de diferentes modos de reflexividade (comunicacional, autónoma e meta-reflexividade) que contribuem para que a prática de voluntariado assuma diferentes formas. A reflexividade comunicacional encontra-se 
ligada a um tipo de voluntários que vê a prática como uma oportunidade de fazer um bom trabalho com e para terceiros; a reflexividade autónoma representa os voluntários que veem a caridade como uma oportunidade de cumprir objetivos pessoais de forma prática (o processo de individualização está bem presente neste perfil); e a meta-reflexividade diz respeito aos voluntários que veem a caridade como a oportunidade de melhorar a sociedade e o mundo. Desta forma, é importante frisar que as estruturas e categorias sociais tradicionais não perderam a sua força com a "chegada" dos processos de reflexividade e individualização (Read, 2010), permanecendo um mix do tradicional com o moderno. Da mesma forma que a modernidade não se "esgotou", também as formas tradicionais de voluntariado não "desapareceram" para dar lugar a novas (Kristiansen, Skille e Hanstad, 2014). Esta postura encontra eco nas palavras de Hustinx e Lammertyn (2000, p. 2): "today's volunteers will combine classical and new features in a 'self-reflexive way'”.

As mudanças e continuidades identificadas ao longo desta secção no que diz respeito ao voluntariado e, em particular, aos indivíduos que o promovem têm, como seria de esperar, impacto sobre as organizações que se envolvem com a prática. Apesar dos desafios que advêm do mix do tradicional com o moderno, muitas delas já adotaram uma postura que permite articular diferentes necessidades, como salienta Hustinx (2010).

\section{O CASO RE-FOOD}

Pensar a prática do voluntariado como sendo, também ela, fruto de um conjunto de transformações que conduzem certos indivíduos, enquanto agentes reflexivos e individualizados, a "exigir" novos tipos de respostas face às suas necessidades, implica responder às seguintes interrogações: Como podemos observar estas necessidades e os processos que conduzem às mesmas? Em que exemplos práticos estas "novas" tendências se tornam mais claras? Como as podemos identificar e caracterizar?

Para tal, e de forma a lançar algumas pistas, recorrer-se-á à análise de uma organização relativamente recente (2011) que fomenta a prática em causa e (sobre)vive graças à mesma. A Re-food é uma associação sem fins lucrativos (com estatuto de IPss), criada por Hunter Halder, que procura combater a fome e o desperdício alimentar através da recolha de alimentos em diversos espaços (cafés, restaurantes e hipermercados, entre outros). Até ao aparecimento desta associação, estes alimentos, que na sua grande maioria já se encontram confecionados, eram deitados para o lixo e, consequentemente, desperdiçados.

$\mathrm{O}$ modelo de funcionamento da associação pode assim ser sintetizado em três passos, expressos na figura que se segue. 
FIGURA 3

Processo de funcionamento da Re-food.
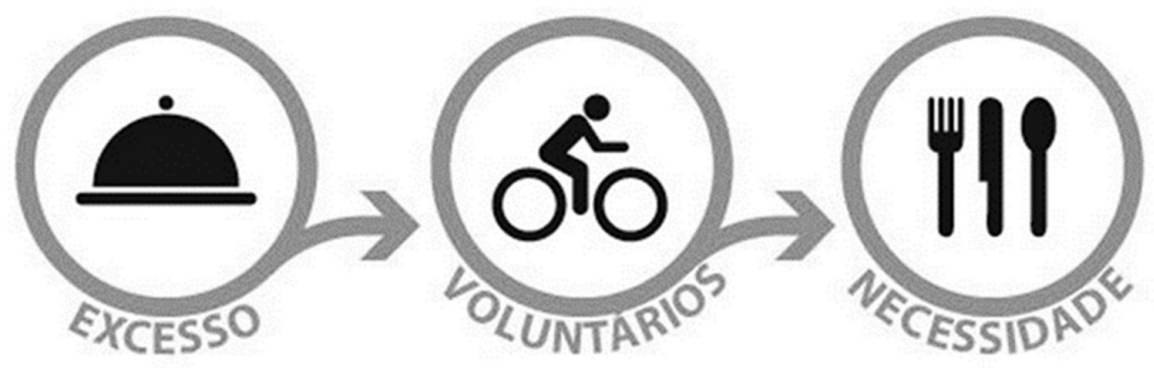

Fonte: Site da Re-food (acedido a 13-12-2016).

O excesso de comida é recolhido por voluntários da Re-food para que seja, posteriormente, distribuído junto daqueles que precisam. Desta forma, de acordo com informação disponibilizada no site da iniciativa, os voluntários podem desenvolver quatro tipos de ações práticas, sendo elas: (i) resgate, onde são cedidos aos parceiros (cafés e restaurantes) os recipientes necessários para que possam armazenar a comida que não foi vendida; (ii) recolha, onde se fazem rotas diárias (a pé, de bicicleta ou de carro) para recolher a comida junto dos parceiros; (iii) embalamento, onde a comida recolhida é dividida e colocada em embalagens familiares; e (iv) distribuição, onde a comida é distribuída tanto nos núcleos como em pontos de distribuição perto das casas dos beneficiários previamente identificados e inscritos. Nos casos de mobilidade reduzida, a distribuição é feita ao domicílio. Geralmente, o voluntariado ocorre uma vez por semana durante duas horas.

A associação conta atualmente com mais de 4000 voluntários que servem cerca de 46000 refeições por mês a mais de 2500 beneficiários. Num espaço de cinco anos (2011-2016), a associação passou de um núcleo, localizado na cidade de Lisboa, para mais de 25 núcleos, distribuídos pelo território nacional (site Re-food).

O desenvolvimento e expansão da Re-food passa, essencialmente, por quatro fases: (i) angariação de membros pioneiros, onde é suposto que os mesmos analisem as necessidades da sua zona, encontrem potenciais parceiros e ajudem no processo de captação de novos voluntários; (ii) realização de uma reunião intitulada "sementeira" ${ }^{8}$, onde se dá a conhecer o projeto e se convidam 
os participantes a colaborar na abertura de um novo núcleo da Re-food; (iii) implementação da estrutura, onde se procede à organização de um espaço e de um grupo de voluntários (que aceitou ajudar através da sementeira) no sentido de dar resposta aos objetivos previamente enunciados; e (iv) início de atividade do novo núcleo Re-food de uma forma regular, coordenada e sustentável, onde se inserem as ações práticas previamente referidas (resgate, recolha, embalamento e distribuição).

Ao representar uma organização que abrange atualmente todo o território português, a Re-food possui um núcleo nacional que serve os diversos núcleos regionais e locais. Cada núcleo local é constituído por um grupo de gestores e coordenadores, cujo papel assenta em manter o bom funcionamento do núcleo (ex. gestão de voluntários e gestão do espaço onde o núcleo opera), sem descurar a identidade e os pressupostos da Re-food (Regulamento Interno Re-food - disponível no site Re-food).

\section{UMA INICIATIVA PERANTE NOVOS E VELHOS DESAFIOS}

A Re-food tem vindo a apresentar um crescimento significativo ${ }^{9}$, aspeto que se deve, sobretudo, à capacidade da iniciativa para cativar a participação da sociedade civil. Justamente por se tratar de uma organização que tem sido capaz de mobilizar pessoas de norte a sul do país, num espaço de tempo relativamente curto, conduz à necessidade de refletir, não só, sobre o modus operandi da iniciativa, como também sobre a forma como ela tem vindo a ultrapassar alguns dos desafios previamente enunciados que se relacionam com a transição para uma nova fase da modernidade num contexto marcado por uma certa "apatia participativa”.

Por intermédio da prática de voluntariado, foi possível compreender algumas das dinâmicas que se estabelecem entre voluntários e beneficiários, mas também entre voluntários e a associação na sua expressão mais vasta (organização, estrutura, missão e valores).

Tal relação envolve, desde logo, um compromisso, onde o voluntário oferece o seu tempo em prol dos objetivos da organização e esta fornece os meios e as condições para que o voluntário possa colaborar. Em torno deste compromisso, vai-se criando uma relação que se pode fragilizar, caso as ambições e expectativas de uma das partes seja defraudada, quer pelo afastamento, incumprimento e/ou incompetência do voluntário ou da organização.

9 Em relação ao número de núcleos, voluntários, beneficiários abrangidos e refeições servidas. 
Os discursos de certos voluntários que fizeram parte da realidade testemunhada pelo voluntário etnógrafo possibilitaram lançar algumas pistas elucidativas quanto à forma como a relação que se estabelece entre voluntários e a organização se regula e também em relação à forma como o já referido mix de expectativas por parte dos voluntários se pode manifestar.

Alguns discursos parecem expressar as necessidades de um tipo de voluntários - mais tradicionais, tal como é descrito por Monteiro (2008) - que valorizam a fidelidade e lealdade à organização em que se inserem:

Gosto daquilo que faço aqui...estou cá quase há dois anos e gosto de fazer a minha recolha... gosto desta rotina... não a alterava por nada! [voluntário, 58 anos].

As coisas têm de ser assim, temos de ter regras, não é? Gosto que assim seja, venho nos meus dias e faço as minhas funções e vou embora... e já lá vão uns aninhos assim... não gostava nada de ter de trocar [voluntária, 46 anos].

Por outro, existem também discursos que apontam para um tipo de voluntário - mais contemporâneo, como referido por Monteiro (2008) - que gere a sua prática em torno de identificações momentâneas, fluídas no tempo e no espaço, e em que o processo de individualização poderá, de facto, estar mais presente e a metáfora do "post-it" pode fazer algum sentido, justamente, pela efemeridade do envolvimento:

Prefiro experimentar coisas diferentes... já estive a fazer voluntariado noutras associações... não gosto de me prender... hoje estou aqui... mas amanhã posso ir para outra causa. [voluntária, 23 anos]

Faço isto para ajudar, mas faço porque me apetece fazer e não porque alguém quer que eu o faça, agora sinto vontade de estar aqui, mas amanhã posso acordar e não querer mais... já estive em vários sítios... a rotina assusta-me [voluntária, 38 anos].

É habitual que no decorrer da prática de voluntariado surjam conversas relacionadas com: (i) o tempo de permanência na iniciativa; (ii) a forma como chegaram até ela; e (iii) os incentivos para a permanência da prática no âmbito daquela organização (e não de outra).

Os discursos apresentados resultam de várias conversas que o voluntário etnógrafo teve a possibilidade de presenciar e que despertaram a sua atenção. Destes diálogos, destaca-se aquele que ocorreu entre um voluntário de 58 anos (primeiro excerto apresentado) que contava já com uma longa relação com a Re-food, estando na mesma há cerca de 3 anos, e uma voluntária de 
23 anos (terceiro excerto apresentado) que havia chegado à iniciativa há cerca de 5 meses. A conversa iniciou-se com o seguinte estímulo, lançado pelo voluntário mais velho: "estás a gostar de estar aqui?", tendo sido este o ponto de partida para a constatação por parte dos atores envolvidos neste diálogo informal de que estavam perante duas perspetivas distintas. De um lado, alguém que não se via a praticar voluntariado fora do contexto da Re-food, valorizando a realidade que já conhecia e lhe era familiar, de outro alguém que não colocava de lado a hipótese de sair da iniciativa assim que o voluntariado na mesma deixasse de fazer sentido para si, tal como já havia acontecido no passado. Interessante também foi o facto de a esta conversa se ter juntado um terceiro elemento, um voluntário de 40 anos, que um pouco indignado e com um tom algo irónico referia: "é por causa de pessoas assim [referindo-se à voluntária de 23 anos] que nos faltam voluntários".

A conversa aqui retratada, que rapidamente cativou a atenção do voluntário etnógrafo, não representou um caso isolado. $\mathrm{O}$ facto de a iniciativa lidar com voluntários regulares (contribuem, pelo menos, $1 \mathrm{~h}$ por mês) e pontuais (não cumprem o requisito anteriormente descrito) ${ }^{10}$ faz com que se abordem questões relacionadas com os fatores que conduzem à permanência ou saída de outros voluntários, sendo notável que se trata de uma questão central no seio da Re-food.

Os relatos apresentados permitem lançar alguns indícios para a existência de uma disparidade de posturas entre os voluntários, sendo possível colocar frente a frente aqueles que se fidelizam e estão confortáveis em realizar o mesmo tipo de atividade em local, hora e data pré-definidos, com aqueles que gostam de experimentar diferentes funções em diferentes contextos associativos. Porém, e tal como foi anteriormente referido, olhar apenas para estes dois tipos de voluntários remete para uma visão simplista de uma realidade bem mais complexa, pelo que se defende a existência de uma multiplicidade de posturas e de combinações das mesmas, onde os níveis de reflexividade e individualização variam. ${ }^{11}$

Enquanto dois jovens voluntários aguardavam dentro do núcleo da Re-food que o tempo melhorasse (dia de chuva intensa) para que pudessem iniciar a recolha de bens alimentares, ocorreu a seguinte conversa:

Voluntário 1: "Está um dia mesmo chato para vir para aqui, não achas? Só vim porque me comprometi e porque me vai ajudar no currículo..." [voluntário, 20 anos]

10 A este respeito ver Franco (2015).

11 À semelhança daquilo que é referido por Sanghera (2017) quando explora diferentes tipos de voluntários e modos de reflexividade. 
Voluntária 2: "A mim custou menos, porque vim direta da universidade... mas não gostas?" [voluntária, 23 anos]

Voluntário 1: "Gosto, gosto... no início custou... vim através de um amigo e achei que me podia ajudar para arranjar trabalho..., mas tenho gostado"

Voluntária 2: Fazes bem, já eu nem no currículo meto...é só mesmo para ajudar, nem ligo a isso... nas entrevistas [de emprego] nem me lembro de dizer...”

A conversa destes dois jovens voluntários da Re-food é, particularmente, interessante para ilustrar as combinações anteriormente referidas e a forma como o projeto individual pode (ou não) ser valorizado em detrimento do projeto coletivo. Se para o voluntário 1 a questão do currículo e da obtenção de um emprego parece ser remetida para primeiro plano, a voluntária 2 atribui centralidade aos objetivos da iniciativa (ligados ao ajudar o outro). O primeiro voluntário a intervir parece assim enquadrar-se na categoria de reflexividade autónoma descrita por Sanghera (2017), em que o processo de individualização estará patente, enquanto o caso da segunda voluntária parece enquadrarse no âmbito da meta-reflexividade.

Desta multiplicidade de posturas e de combinações das mesmas advêm os supramencionados desafios no acolhimento. Perante os mesmos, a Re-food preocupa-se em fornecer, desde logo, aos seus voluntários a possibilidade de optarem pela atividade com que se sentem mais confortáveis (ex. recolha, tratamento e entrega de bens alimentares), onde as competências adquiridas ao longo da vida podem ou não pesar no momento de tomada de decisão:

Eu prefiro ir buscar comida... detesto ficar parado no mesmo sítio...não gosto da parte de mexer na comida. ${ }^{12}$ [voluntário, 58 anos]

Eu vim para ajudar as pessoas e gosto de ver a alegria na cara delas e gosto que me digam "obrigado", gosto de andar na carrinha a entregar. [voluntário, 36 anos]

Além disso, os voluntários não necessitam de realizar o mesmo tipo de atividade, eles têm autonomia para experimentar outras formas de ajudar, desde que, informem o/a gestor/a de turno ${ }^{13}$ e este/a mesma consiga satisfazer as suas necessidades:

12 Refere-se ao processo de embalamento anteriormente mencionado.

13 Responsável por gerir e articular a disponibilidade e as preferências dos voluntários com as necessidades da Re-food, particularmente, do núcleo em causa. 
Já estive na cozinha... já entreguei e já andei com o carro, mas agora estou mais na cozinha outra vez... acho que é melhor... eles deixam as pessoas fazer várias coisas... isso é bom! [voluntária, 47 anos].

Esta liberdade de escolha tem garantido a permanência de voluntários que não se revêm em modelos mais inflexíveis, com atividades, local e horários fixos:

Já fiz muita coisa aqui... gosto de ver tudo... e já vi quase tudo... se não me deixassem fazer o que eu quero também já me tinha ido embora [voluntária, 54 anos].

Estes discursos foram emergindo, frequentemente, durante a prática do voluntariado. Tal como foi referido, os voluntários acabam por partilhar, de forma relativamente natural, as suas experiências na Re-food, bem como aquilo que os leva a permanecer na iniciativa. $\mathrm{O}$ último excerto apresentado, da voluntária de 54 anos, acaba por espelhar uma das grandes preocupações das iniciativas que promovem o voluntariado, que se prende com a necessidade de cativar para a prática em causa.

A Re-food possui, desta forma, alguns elementos caracterizadores que lhe permitem adaptar-se a uma realidade onde existem diferentes tipos de voluntários, tendo em conta os seus interesses e expectativas. Contudo e embora a Re-food seja capaz de promover a participação sob a forma de voluntariado e disponibilize um alargado leque de experiências, ela lida com voluntários que assumem diferentes tipos de compromisso para com a iniciativa. Este compromisso pode ser de longa ou curta duração e pode assentar sobre diversos tipos de motivações. Assim, o processo de captação de voluntários assume centralidade face à existência de diferentes modalidades de fidelização.

\section{UMA INSTRUMENTALIZAÇÃO A DOIS RITMOS?}

Perceber aquilo que motiva alguém a colaborar sobre a forma de voluntariado tem constituído o mote para diversos estudos científicos (Rego, Zózimo e Correia, 2017). Entre as várias motivações que têm vindo a ser identificadas, encontram-se as de carácter (mais) instrumental (Rego, Zózimo e Correia, 2017), nas quais o voluntariado se assume como um investimento e como uma possibilidade de alcançar determinados objetivos individuais (o projeto do "eu"), como por exemplo, aceder ao mercado de trabalho.

Assim, é possível encontrar uma multiplicidade de motivações para o voluntariado, sejam estas de ordem mais altruísta ou de ordem mais instrumental. 
Se é verdade que as primeiras parecem caracterizar a própria prática, também é verdade que as últimas parecem criar pontos de rutura com a mesma (Rego, Zózimo e Correia, 2017). Contudo, e como já foi referido, é possível que um mesmo sujeito combine várias motivações e que estas vão sofrendo transformações ao longo do tempo.

O discurso do voluntário 1, anteriormente apresentado, espelha uma motivação de carácter instrumental, que passa por investir o seu tempo na iniciativa com o intuito de melhorar o seu currículo para que possa, mais tarde, conseguir um emprego na sua área de formação. As motivações instrumentais, em particular, ligadas ao acesso ao mundo do trabalho adquirem particular expressão junto de voluntários jovens que se encontram a dar os primeiros passos enquanto profissionais (Delicado, Almeida e Ferrão, 2002), como se prevê que seja o caso do voluntário 1 .

Se, por um lado, é possível constatar a existência de motivações de ordem instrumental no contexto da Re-food, também é possível afirmar que a organização é capaz de percecionar e utilizar em seu benefício tais motivações, tornando assim provável a existência de um processo de instrumentalização que ocorre a dois ritmos: por parte dos voluntários e por parte da organização que os acolhe.

No âmbito da observação participante, o voluntário etnógrafo apercebeu-se de que a Re-food foca grande parte da sua atenção e recursos na captação de voluntários junto das universidades. Esta aposta assenta no pressuposto de que os jovens universitários têm tempo, capacidades e interesse em participar. Ora, este interesse pode estar associado às referidas motivações instrumentais:

Temos conseguido muitos voluntários nas universidades, eles são novos e gostam destas coisas... também é bom para eles, principalmente, para quando quiserem um trabalho... isto vale muito no currículo... só é pena que não se mantenham por muito tempo... ficam uns meses e vão à vida deles [voluntária, 45 anos].

O discurso desta voluntária, que desempenha a função de gestora de turno, lança algumas pistas sobre o pensamento que poderá estar nos "bastidores" do processo de captação. A ideia de que a Re-food pode satisfazer uma necessidade instrumental dos voluntários e fazer-se valer dela para os cativar parece fazer sentido:

Voluntário 3: "Não é fácil gerir pessoas aqui, aliás, não é fácil gerir pessoas... ponto final... os que veem das universidades têm outras ideias... querem pôr no currículo e ir embora... alguns nem avisam... vão e pronto" [voluntário, 33 anos]. 
Voluntária 4: "Nas reuniões já falámos desse problema, mas eles são muito úteis, ainda que por curtos períodos de tempo..." [voluntária, 46 anos].

Esta conversa, levada a cabo por outros dois gestores de turno, acaba por reforçar a ideia de que poderá, de facto, existir um processo de instrumentalização do voluntariado que ocorre a duas "velocidades" no contexto da Re-food. Apesar de existir um entendimento mais ou menos generalizado sobre o valor e a necessidade de cativar um tipo de voluntários específico (jovens universitários), ele coexiste com o conhecimento de que estes voluntários acarretam desafios ligados, sobretudo, ao facto de não permanecerem na iniciativa por longos períodos de tempo.

Tendo em conta este processo de instrumentalização do voluntariado, onde a prática é valorizada enquanto fenómeno potenciador de empregabilidade, Rego, Zózimo e Correia (2017) discutem a implementação de um sistema de validação das aprendizagens informais como possível estratégia para que exista uma maior valorização do voluntariado no mercado de trabalho. Apesar de tanto o processo de instrumentalização como de implementação de um sistema de validação de competências levantarem questões relacionadas com a própria prática do voluntariado e aquilo que ela representa, eles não implicam "necessariamente o fim do espírito generoso e desinteressado que se associa ao voluntariado" visto que ele continua a ser de "adesão livre" (Rego, Zózimo e Correia, 2017, p. 94).

Apesar de a Re-food ser capaz de cativar um grupo bastante heterogéneo de voluntários - que combinam diferentes características e motivações - e de focar, estrategicamente, os seus esforços de captação em grupos específicos, a iniciativa depara-se com diversos desafios, onde se destaca a dificuldade em gerir voluntários com expectativas e interesses diferentes associados ao voluntariado e, em particular, à organização. Ora, se por um lado, interesses de ordem instrumental podem colocar em causa o funcionamento da iniciativa pelo carácter instável da fidelização, por outro, a própria Re-food parece conhecer e aceitar esta realidade, apostando, portanto, no desconhecido e indo ao encontro de "fidelizações" de carácter mais efémero.

\section{CONSIDERAÇÕES FINAIS}

O voluntariado e, particularmente, as modalidades de envolvimento em torno desta prática têm vindo a enfrentar os impactos resultantes da transição para uma segunda fase da modernidade. A este respeito, destaca-se a perda de certas referências identitárias e um certo processo de empoderamento dos sujeitos na construção das suas próprias biografias. Fruto destes processos, o voluntariado 
encontra-se envolto de tensões, que resultam, por um lado, da permanência dos valores de solidariedade frequentemente associados ao fenómeno e, por outro, da emergência de relações que se passam a gerir em função de interesses individuais.

Os números relativos ao voluntariado em Portugal apontam para uma certa "apatia participativa", que se traduz na existência e permanência de baixas taxas de voluntariado nas suas diversas tipologias (formal, informal e de proximidade). Além dos números, um conjunto de transformações sociais conduziu a que processos como a individualização e a reflexividade tivessem impacto no voluntariado e na forma como os indivíduos o veem e experienciam, coexistindo, atualmente, diversos perfis de voluntários.

Face a um contexto (o nacional) e a uma realidade (valorização do projeto individual) onde é possível encontrar uma multiplicidade de interesses e expectativas, emergem diversos desafios para as organizações que promovem o voluntariado. Se é verdade que a prática se encontra, geralmente, associada a atos altruístas através dos quais o indivíduo age em prol do "outro", também é verdade que motivações de ordem instrumental têm vindo a ganhar expressão, e nestas o voluntariado assume-se como um meio para alcançar objetivos individuais, relacionados com o projeto do "eu" (ex: obtenção de emprego).

A Re-food surge assim como uma iniciativa que tem "prosperado" num contexto onde a prática do voluntariado não adquiriu (ainda) uma expressão significativa, e num contexto de profundas mudanças, no qual é possível encontrar interesses, expectativas, motivações e valores associados ao voluntariado que se orientam em torno destes dois polos.

Apercebendo-se da existência de motivações de ordem instrumental, a Re-food, ela própria, parte para a instrumentalização da prática ao direcionar o processo de captação para um público específico, sobretudo universitário, que se encontra, geralmente, numa fase da vida em que a construção de um currículo que seja aliciante para as futuras entidades empregadores representa um objetivo central.

Além disso, a iniciativa promove uma "experiência” de voluntariado flexível, disponibilizando um alargado leque de ações que o voluntário pode realizar. Apesar de se tratar de uma iniciativa recente, ela já atua a nível nacional, o que se deve, sobretudo, ao facto de o seu modus operandi promover uma replicação relativamente simples e rápida. Porém, ao tratar-se de uma organização $100 \%$ voluntária, ela necessita de continuar a cativar a participação da sociedade civil, o que pode colocar em causa a sua continuidade, principalmente face à previamente referida "apatia participativa” espelhada pelos números. 
Em suma, a análise aqui apresentada procurou enquadrar teoricamente a prática do voluntariado no âmbito de um conjunto de transformações sociais que conduziram a uma valorização do projeto individual (do "eu"), que se concilia com uma maior expressão de interesses e motivações de ordem instrumental em torno da prática. Neste âmbito, foi apresentado um exemplo empírico de uma iniciativa (Re-food) que mostra indícios destas transformações e "interage" com as mesmas num contexto em que o voluntariado ainda representa uma prática com pouca expressão.

Porém, a análise é sustentada num conjunto de discursos que foram obtidos no âmbito da observação participante realizada pelo voluntário etnógrafo, pelo que seria interessante em investigações futuras realizar uma análise mais extensiva e intensiva da prática, dos seus atores e das organizações. Desta forma, o presente artigo procurou realizar um esboço de um retrato de uma realidade bem mais abrangente e complexa daquela que aqui é descrita. A análise centrou-se num dos vários núcleos da Re-food e a observação foi realizada em horário específico, pelo que os resultados não devem ser generalizados no âmbito da própria iniciativa, ainda que se preveja a transversalidade de algumas das conclusões apresentadas. ${ }^{14}$

$14 \mathrm{O}$ autor agradece o apoio financeiro concedido pela Fundação para a Ciência e a Tecnologia (FCT) através da atribuição de uma bolsa de investigação, com a referência SFRH/ BD/130072/2017, no âmbito do Programa Operacional Capital Humano (POCH), comparticipado pelo Fundo Social Europeu (FSE) e por fundos nacionais do Ministério da Ciência, Tecnologia e Ensino Superior (MCTES). 


\title{
REFERÊNCIAS BIBLIOGRÁFICAS
}

\author{
FONTES
}

SITE DA RE-FOOD. Disponível em: http://www.re-food.org/pt [consultado em 13-12-2016].

*

Amaro, R. et al. (coord) (2012), Estudo de Caracterização do Voluntariado em Portugal, Lisboa, Conselho Nacional para a Promoção do Voluntariado.

Bauman, Z. (2001[2000]), Modernidade Líquida, Rio de Janeiro, Jorge Zahar Editor.

BECK, U. (1992), Risk Society: Towards a New Modernity, Londres, Sage Publications.

Beck, U. (1999), The Reinvention of Politics: Rethinking Modernity in the Global Social Order, Cambridge, Polity Press.

BECK, U. (2002), "Zombie categories: an interview with Ulrich Beck". In U. Beck, E. Beck-Gernsheim (eds.), Individualization: Institutionalized Individualism and its Social and Political Consequences, Londres, SAGE, pp. 202-213.

BECK, U. (2008), World Risk Society, Cambridge, Polity Press.

BECK, U., BECK-GERNSheim, E. (2002), Individualization, Londres, Sage Publications.

BeCK, U., Giddens, A. e LASH, S. (2000), Modernização Reflexiva - Política, Tradição e Estética no Mundo Moderno, Oeiras, Celta Editora.

Charities AID foundation (2011), World Giving Index 2011: A Global View of Giving Trends, UK, Charities Aid Foundation.

Charities AID Foundation (2012), World Giving Index 2012: A Global View of Giving Trends, UK, Charities Aid Foundation.

Charities AID Foundation (2013), World Giving Index 2013: A Global View of Giving Trends, UK, Charities Aid Foundation.

Charities AID Foundation (2014), World Giving Index 2014: A Global View of Giving Trends, UK, Charities Aid Foundation.

CHARITIES AID Foundation (2015), World Giving Index 2015: A Global View of Giving Trends, UK, Charities Aid Foundation.

CHARITIES AID FOUNDATION (2016), CAF World Giving Index 2016: The World's Leading Study of Generosity, UK, Charities Aid Foundation.

delicado, A., Almeida, A. e ferrão, J. (2002), Caracterização do Voluntariado em Portugal, Lisboa, Comissão Nacional para o Ano Internacional do Voluntariado.

ferreira, S., SERAPioni, M., MANeCA, T. (2013), Voluntariado em Portugal: Contextos, Atores e Práticas, 1. ${ }^{\mathrm{a}}$ ed., Évora, Fundação Eugénio de Almeida.

FRANCO, R. C. (2015), Diagnóstico das ONG em Portugal, Lisboa, Fundação Calouste Gulbenkian. Garthwaite, K. (2016), “The perfect fit? Being both volunteer and ethnographer in a uK foodbank”. Journal of Organizational Ethnography, 5(1), pp. 60-71.

GIDDEns, A. (1990), The Consequences of Modernity, Stanford, Stanford Univiversity Press.

GIdDens, A. (1997), "Risco, confiança e reflexividade”. In U. Beck, A. Giddens, S. Lash (eds.), Modernização Reflexiva, São Paulo, Editora da Universidade Estadual Paulista.

HARDILL, I., BAINES, S. (2011), Enterprising Care: Unpaid Voluntary Action in the 21st Century, Bristol, Policy Press.

HUSTINX, L. (2010), "Institutionally Individualized Volunteering: Towards a Late Modern ReConstruction". Journal of Civil Society, 6(2), pp. 165-179. 
HUStinx, L., LAMmertyn, F. (2000), "Solidarity and volunteering under a reflexive-modern sign: towards a new conceptual framework". Paper presented to IsTR's Fourth International Conference, Disponível em https://biblio.ugent.be/publication/1123214 [consultado em 15-01-2017].

HUSTINX, L., LAMMERTYN, F. (2003), “Collective and reflexive styles of volunteering: a sociological modernization perspective". Voluntas: International Journal of Voluntary and Nonprofit Organizations, 14(2), pp. 167-187.

HUSTINX, L., LAMMERTYN, F. (2004), “The cultural bases of volunteering: understanding and predicting attitudinal differences between Flemish Red Cross volunteers". Nonprofit and Voluntary Sector Quartely, 33(4), pp. 548-584.

KRISTIANSEN, E., SKILLE, E., e HANSTAD, D. V. (2014), "From community based identities to individual benefits for volunteers: a comparison of three sporting events". Scandinavian Sports Studies Forum, 5, pp. 47-68.

monteiro, A. (2004), Associativismo e Novos Laços Sociais, Coimbra, Quarteto.

MONTEIRo, A. (2008), "Quando a ajuda chega por mail: o voluntariado online como oportunidade e realidade”. Atas do vi Congresso Português de Sociologia, pp. 1-15.

READ, R. (2010), "Creating reflexive volunteers? Young people's participation in Czech hospital volunteers programmes". Journal of Youth Studies, 13(5), pp. 549-563.

Rego, R., zózimo, J., CORReiA, M. J. (2017), "Voluntariado em Portugal: do trabalho invisível à validação de competências”. Sociologia, Problemas e Práticas, 83, pp. 75-97.

SANGHerA, B. (2017), "Charitable giving and reflexive individuals: How personal reflexivity mediates between structure and agency”. Social Science Information, 56(1), pp. 28-48.

SANTOS, B.S. (1993), "O Estado, as relações salariais e o bem-estar social na semiperiferia: o caso português”. In B.S. Santos (org.), Portugal: um Retrato Singular, Porto, Afrontamento, pp. $15-56$.

santos, B.S. (1995), “Sociedade-Providência ou Autoritarismo Social?”. Revista Crítica de Ciências Sociais, 42, pp. 1-4.

WILSON, A., PIMM, G. (1996), "The tyranny of the volunteer: The care feeding of voluntary work-forces”. Management Decision, 34(4), pp. 24-40.

Recebido a 01-11-2017. Aceite para publicação a 30-11-2019.

AUgusto, F. R. (2020), "Expressões do voluntariado: entre o projeto coletivo e o individual”. Análise Social, 234, LV $\left(1 .^{\circ}\right)$, pp. 144-167.

Fábio Rafael Augusto » fabio.augusto@ics.ulisboa.pt " Instituto de Ciências Sociais, Universidade de Lisboa " Av. Professor Aníbal de Bettencourt, 9 - 1600-189 Lisboa, Portugal » https://orcid.org/oooo$0002-1957-2477$. 